\title{
Characterization of Grain Boundaries in Superplastically Deformed Y-TZP Ceramics
}

\author{
Michel M. R. Boutz, ${ }^{\dagger}$ Chu Sheng Chen, Louis Winnubst, ${ }^{*+t}$ and Anthonie J. Burggraaf \\ Laboratory for Inorganic Chemistry, Materials Science and Catalysis, Faculty of Chemical Technology,
} University of Twente, Enschede, The Netherlands

\begin{abstract}
The effects of compressive deformation on the grain boundary characteristics of fine-grained Y-TZP have been investigated using surface spectroscopy, impedance analysis, and transmission electron microscopy. After sintering at low temperature $\left(1150^{\circ} \mathrm{C}\right)$, the grain boundaries are covered by an ultrathin $(1 \mathrm{~nm})$ yttrium-rich amorphous film. After deformation at $1200^{\circ}-1300^{\circ} \mathrm{C}$ under low stress, some grain boundaries are no longer covered by the amorphous film. Yttrium segregation seems to occur only at wetted grain boundaries. Evidence has been found that the extent of dewetting increases with increasing applied stress.
\end{abstract}

\section{Introduction}

$\mathbf{P}$ OLYCRYSTALLINE zirconia ceramics are used for both electrical and mechanical applications. These materials invariably contain impurities introduced during synthesis and processing of the starting powders. Silica and alumina are the most frequently encountered impurities: they originate mostly from the zirconium source $\left(\mathrm{ZrSiO}_{4}\right.$ or products derived from this raw materal) or from milling media (alumina or porcelain balls). During sintering of zirconia ceramics, the presence of these impurities leads to the formation of an amorphous silicate phase, which is liquidlike at high temperatures and wets the grain boundaries. The degree of wetting and the composition of this amorphous silicate phase have a strong influence on both the electrical ${ }^{1}$ and superplastic deformation ${ }^{2.3}$ characteristics of zirconia.

Transmission electron microscopy (TEM) observations ${ }^{4.5}$ have shown that in yttria-stabilized tetragonal zirconia polycrystals (Y-TZP) this amorphous phase is present either as a thin $(1-5 \mathrm{~nm}$ ) continuous film at grain boundaries (two-grain junctions) or as pockets at multiple-grain junctions. The distribution of this amorphous phase strongly depends on its composition and thermomechanical history. Several ceramic processing parameters such as sintering and annealing temperature ${ }^{6}$ cooling rate, ${ }^{7}$ and pressure treatments ${ }^{8}$ affect the nature and location of the amorphous phase.

The superplastic deformation behavior of Y-TZP is especially sensitive to the amount and composition of the "glassy" phase. Nauer and Carry ${ }^{9}$ observed a difference in strain rates by one order of magnitude between two Y-TZP batches differing only in residual impurity content. Yoshizawa and Sakuma ${ }^{3}$ found that the temperature needed to obtain strain rates of $10^{-4}$ $\mathrm{s}^{-1}$ at a stress level of $20 \mathrm{MPa}$ could be lowered from $1350^{\circ} \mathrm{C}$ for "pure" Y-TZP to $1100^{\circ} \mathrm{C}$ by addition of $5 \mathrm{wt} \%$ of a lithium silicate glass. Hwang and $C$ hen ${ }^{10}$ could increase the strain rate

D. R. Clarke-contributing editor

Manuscript No. 194088. Rcceived November 1, 1993; approved March 28, 1994.

Supported by Akzo Chemicals B. V., The Netherlands

${ }^{\star}$ Member, American Ceramic Society.

'Present address: Advanced Ceramics Group, TU Hamburg-Harburg, 21071 Hamburg, Germany.

Author to whom correspondence should be addressed. of $2 \mathrm{Y}$-TZP by more than one order of magnitude by addition of $0.3 \mathrm{wt} \% \mathrm{CuO}$.

The deformation behavior of fine-grained (grain size $0.2 \mu \mathrm{m}$ ) Y-TZP materials, produced via a gel precipitation technique using metal chlorides as precursor chemicals ("chloride" method), has been reported previously. "Deformation of these materials proceeds via grain boundary sliding. Interface reactions (attachment or detachment of diffusing species) are found to be rate-controlling under the investigated experimental conditions $\left(1100^{\circ}-1300^{\circ} \mathrm{C}, 16-120 \mathrm{MPa}\right)$. It has been observed that during compression of these materials at $1100^{\circ}-1300^{\circ} \mathrm{C}$ under constant stresses of $20-40 \mathrm{MPa}$ the strain rate is decreasing continuously. This could not be explained on the basis of grain growth, but could possibly be related to changes in grain boundary chemistry.

Although there is general agreement that the composition of the intergranular silicate film and the degree of coverage of the grain boundaries by this film has a strong impact on the superplastic deformation behavior of Y-TZP, no extensive study of the grain boundaries of superplastically deformed Y-TZP has been performed so far. To gain insight in the changes in grain boundary chemistry of Y-TZP caused by compressive deformation, an analysis of grain boundaries before and after compression has been performed using different techniques. X-ray photoelectron spectroscopy (XPS) has been used extensively to analyze the grain boundary composition and to determine the chemical environment of the different elements. Additional information was provided by scanning auger microscopy (SAM), impedance spectroscopy (IS), and transmission electron microscopy (TEM).

\section{Experimental Procedure}

\section{(1) Investigated Materials, Thermomechanical Treatments}

Three powder batches of $2.6 \mathrm{~mol} \% \mathrm{Y}_{2} \mathrm{O}_{3}$-stabilized tetragonal zirconia have been prepared by the "chloride" method. ${ }^{12}$ The residual impurity content as analyzed by flameless atomic absorption spectroscopy (AAS) of these powder batches (code names ChL, where $x$ is 1,2 , or 4) can be found in Table I. After isostatic compaction in two steps $(100 \mathrm{MPa}$, followed by 400 $\mathrm{MPa}$ ) all samples were sintered in air at $1150^{\circ} \mathrm{C}$ during $10-12 \mathrm{~h}$ and cooled down slowly $\left(180^{\circ} \mathrm{C} / \mathrm{h}\right)$ to room temperature, followed by machining to the appropriate dimensions. In the case of batches $\mathrm{Chl} 1$ and $\mathrm{Chl} 2$, specimens were first sintered at $1100^{\circ} \mathrm{C}$ for $12 \mathrm{~h}$ before sintering at $1150^{\circ} \mathrm{C}$. The density of all specimens used for compression tests was above $95 \%$ of theoretical $\left(6.06 \mathrm{~g} / \mathrm{cm}^{3}\right)$.

Table I. Impurity Content (wt \%) of the Investigated Powder Batches

\begin{tabular}{lccccc}
\hline Powder batch & $\mathrm{Na}$ & Fc & Al & Si & Total \\
\hline Chl1 & 0.0031 & 0.0020 & 0.1600 & 0.0290 & 0.1941 \\
Ch12 & 0.0045 & 0.0010 & 0.1700 & 0.1100 & 0.2855 \\
Chl4 & 0.0115 & 0.0056 & 0.0027 & 0.0009 & 0.0208 \\
\hline
\end{tabular}


Constant-stress experiments were performed on rectangular $(7 \mathrm{~mm} \times 7 \mathrm{~mm} \times 21 \mathrm{~mm})$ specimens of materials Chll and Chl2 using a screw-driven testing machine (model 1361, Instron, U.K.). Compression tests were performed in air at $1100^{\circ}-1300^{\circ} \mathrm{C}$ under stresses of $16-120 \mathrm{MPa}$. Specimens were heated at $1000^{\circ} \mathrm{C} / \mathrm{h}$ to $1000^{\circ} \mathrm{C}$, followed by heating at $1500^{\circ} \mathrm{C} / \mathrm{h}$ to the final temperature. Such high heating rates prevent microstructural changes taking place during heating. After compression to a true strain of 0.5 , the samples were rapidly cooled under load to conserve the high-temperature microstructure. The macroscopic flow behavior observed during these compression tests has been described elsewhere. ${ }^{11}$

Constant-load experiments were carried out at $1250^{\circ} \mathrm{C}$ on cylindrical samples (height $8.5 \mathrm{~mm}$, diameter $6.5 \mathrm{~mm}$ ) of material Chl4 using a hydraulic compression machine (Elatec, Finland). Samples were heated at $300^{\circ} \mathrm{C} / \mathrm{h}$ to $1250^{\circ} \mathrm{C}$, compressed to a true strain of 0.5 under initial stresses of 20,60 , and $100 \mathrm{MPa}$, and cooled to room temperature at $300^{\circ} \mathrm{C} / \mathrm{h}$ after the load had been released. The time necessary to reach 0.5 true strain decreased from 120 min under $20 \mathrm{MPa}$ to $15 \mathrm{~min}$ under $100 \mathrm{MPa}$. To evaluate the effect of temperature only, samples of the Chl4 material were annealed in the Elatec machine without applying a load. The relevant data of the final thermomechanical treatment of the analyzed samples can be found in Table II.

Materials Chl1 and Chl 2 were characterized by XPS, SAM, and TEM, while IS measurements were done on material Chl4. The very fine-grained, dense zirconia materials investigated here (grain size $<0.3 \mu \mathrm{m}$ ) could all be fractured intergranularly. Fracture surfaces could therefore be used to analyze grain boundary compositions by XPS and SAM. The XPS apparatus did not possess a fracturing device inside the UHV system, and specimens were therefore fractured under ambient conditions. After fracturing, samples were immediately inserted in the sample chamber of the surface analysis equipment.

\section{(2) X-ray Photoelectron Spectroscopy}

$\mathrm{X}$-ray photoelectron spectra were recorded in a Kratos XSAM-800 with $\mathrm{Mg} K \alpha$ radiation (1253.6 eV, 300-375 W) operating at pressures below $6 \times 10^{-4}$ torr $\left(\sim 8.0 \times 10^{-7} \mathrm{~Pa}\right)$. Stainless steel sample holders were used. To correct for surface charging, the binding energy (BE) of the $\mathrm{Zr} 3 d_{5 / 2}$ line has been fixed at $182.2 \mathrm{eV}{ }^{6}$ The applied corrections for charging were equal to $3-5 \mathrm{eV} \mathrm{BE}$. The observed binding energy of the $\mathrm{C} 1 \mathrm{~s}$ peak of adventitious carbon using this correction method was close to the literature value $(284.6 \mathrm{eV})$. Peak positions have been determined from the original spectrum (corrected for charging) and from its second derivative. ${ }^{13}$

Depth profiles were obtained by $\mathrm{Ar}^{+}$-ion sputtering (3.5 $\mathrm{keV}$ ) with an estimated sputter rate of $1 \AA / \mathrm{min}$ for $\mathrm{Ta}_{2} \mathrm{O}_{5}$. The angle between the $\mathrm{Ar}^{+}$ion beam and the sample surface during sputtering was approximately $45^{\circ}$. A circular area with a diameter of $2-3 \mathrm{~mm}$ has been analyzed.

To identify the main elements present at the grain boundaries, survey scans $(0-1100 \mathrm{eV} \mathrm{BE})$ were recorded before and

Table II. Thermomechanical Treatment (Initial Grain Size $0.21 \mu \mathrm{m}$ ) of the Investigated Samples

\begin{tabular}{|c|c|c|c|c|c|}
\hline $\begin{array}{l}\text { Sample } \\
\text { number }\end{array}$ & Material & $\begin{array}{c}\text { Temperature } \\
\left({ }^{\circ} \mathrm{C}\right)\end{array}$ & $\begin{array}{c}\text { Time } \\
(\mathrm{h})\end{array}$ & $\begin{array}{l}\text { Stress } \\
\text { (MPa) }\end{array}$ & Remarks \\
\hline 1 & Chl1 & 1150 & 12 & & Sintered \\
\hline 2 & Ch11 & 1150 & 12 & & Sintered \\
\hline 3 & Chll & 1300 & 1.3 & $20^{*}$ & Compressed \\
\hline 4 & Chl2 & 1150 & 12 & & Sintered \\
\hline 5 & $\mathrm{Chl} 2$ & 1250 & 5.9 & $20 *$ & Compressed \\
\hline \multirow[t]{2}{*}{6} & Chl2 & 1100 & 4.3 & $20-40$ & Compressed \\
\hline & & 1200 & 2.7 & $20-120$ & \\
\hline 7 & Chl4 & 1150 & 10 & & Sintered \\
\hline 8 & Chl4 & 1250 & 2.0 & 20 & Compressed \\
\hline 9 & Chl4 & 1250 & 0.5 & 60 & Compressed \\
\hline 10 & Chl4 & 1250 & 0.25 & 100 & Compressed \\
\hline
\end{tabular}

*Interrupted by stress jumps to 16 and $24 \mathrm{MPa}$. after sputtering. Depending on the concentration of the element, the spectral regions of interest for quantification were recorded several (up to 20) times to obtain good signal-to-noise ratios. Background corrections were performed using the nonlinear method of Shirley. ${ }^{14}$ Empirically derived atomic sensitivity factors ${ }^{15}$ have been used. The following photoelectron lines have been used for quantification: $\mathrm{A} 12 p, \mathrm{Si} 2 s, \mathrm{Y} 3 d, \mathrm{Zr} 3 d, \mathrm{C} 1 s, \mathrm{O} 1 s$, $\mathrm{F} 1 s$, and Na1s. The information depth of the photoelectrons used for analysis lies in the range 5.2-6.6 nm, except for the $\mathrm{Na}$ ls line, which possesses a much shallower information depth $(2.6 \mathrm{~nm}) .{ }^{16}$

Deconvolution has been performed with the software package supplied by Kratos to the Kratos XSAM-800 apparatus. Suitability of curve fits was based on statistical (goodness-offit) and physical (halfwidths) considerations.

\section{(3) Transmission Electron Microscopy}

Thin foils used for TEM observations were prepared from slices ground to $0.1-\mathrm{mm}$ thickness with $\mathrm{SiC}$ paper, followed by mechanically polishing to $50-60 \mu \mathrm{m}$ using diamond abrasives. Disks (diameter $3 \mathrm{~mm}$ ) were thinned to electron transparency by dimple grinding followed by argon ion milling or by direct argon ion milling. TEM observations were performed with several microscopes: at $300 \mathrm{keV}$ (Philips EM 430 ST or CM 30 ST, Eindhoven, Netherlands) or at $200 \mathrm{keV}$ (JEOL JEM $2010 \mathrm{HT}$, Peabody, MA). For EDS analysis (EDAX) with the Philips CM $30 \mathrm{ST}$, the sample was tilted to $15^{\circ}-25^{\circ}$; the spot size equalled $5 \mathrm{~nm}$ for grain interior analysis and could be further narrowed to $2.5 \mathrm{~nm}$ for grain boundary analysis. Due to beam spreading within the sample, the spatial resolution of the EDS analysis is larger than the spot size.

The presence of thin amorphous films at grain boundaries has been investigated by the Fresnel fringe and the lattice fringe imaging technique. More details of these microscopy techniques can be found elsewhere. ${ }^{17}$

\section{(4) Scanning Auger Microscopy}

SAM measurements were performed on a Phi 600 (Physical Electronics, Edina, MN) SAM. Analyses were carried out using a primary beam energy of $3 \mathrm{keV}$ and an electron beam current of $50-100 \mathrm{nA}$. The analyzed area was $25 \mu \mathrm{m}^{2}$. The angle between electron beam and the fracture surface was set at approximately $30^{\circ}-40^{\circ} \mathrm{C}$ to minimize charging. The equation of Davis et al. ${ }^{18}$ has been used for quantification. The spectral regions were scanned several (up to 50) times in an effort to obtain good signal-to-noise ratios. Only low beam currents could be used to avoid charging of the sample. However, even with a beam current of $50 \mathrm{nA}$, severe charging occurred after removal of most of the adventitious carbon during the first sputtering step $(1 \mathrm{~min})$. Furthermore, the intensities of the Auger lines of the impurity cations and the well-separated, highenergy peaks of $\mathrm{Zr}$ and $\mathrm{Y}$ were insufficient for quantification with this beam current.

Therefore, only an estimate of the $\mathrm{Y} / \mathrm{Zr}$ ratio before sputtering (when charging is reduced due to the presence of adventitious carbon) has been made, using the method proposed by Winnubst et al. ${ }^{19}$ for sintered samples. Briefly, the method consists of measuring the positive part of the Y MNN Auger line at $77 \mathrm{eV}$ with respect to the baseline and multiplying by 2 to obtain peak-to-peak intensity. Only the positive part of this line is free from overlap with the 92-eV $\mathrm{Zr}$ Auger line. No other Y line can be used in the low-energy region, because of severe overlap with $\mathrm{Zr}$ lines. The $140-\mathrm{eV} \mathrm{Zr}$ MNN line is not disturbed by overlap and was used for quantification. Calibrated sensitivity factors were taken from Ref. 19. This analysis should be considered as being semiquantitative.

\section{(5) Impedance Spectroscopy}

ac complex impedance spectra were recorded with a Solartron 1255 frequency response analyzer in the frequency range $10^{-3}-10^{6} \mathrm{~Hz}$ at $300^{\circ}-600^{\circ} \mathrm{C}$ in air. Only results obtained at $341^{\circ} \mathrm{C}$ will be presented here, since the grain boundary and 
the grain interior semicircles are well-separated at this temperature. Platinum electrodes were attached to disk-shaped samples by sputtering (in such a way that the current was parallel to the compression axis), followed by annealing at $950^{\circ} \mathrm{C}$ for $2 \mathrm{~h}$. By plotting the imaginary part $\left(-Z^{\prime \prime}\right)$ of the conventional impedance $(Z)$ versus its real part $\left(Z^{\prime}\right)$ at different frequencies, one obtains the complex impedance spectrum. ${ }^{20}$ The impedance spectra have been interpreted in terms of the brick layer model proposed by van Dijk and Burggraaf. ${ }^{21}$ More details about the data analysis can be found elsewhere. ${ }^{22}$

Of particular interest in this investigation are the grain boundary resistivity and capacitance. The grain boundary resistivity arises from the partial or complete blocking of charge carriers due to the presence of impurities at the grain boundaries or because of intrinsic effects (e.g., space charges, lattice mismatching, host lattice cation segregation). ${ }^{23}$ The macroscopic grain boundary resistivity normalized for specimen dimensions $\left(R_{\mathrm{gh}}^{\text {mac }}\right)$ is also affected by the average grain size of the specimen. Since the grain boundary area per unit of material volume decreases with increasing grain size $(D)$, it is most appropriate to correct for this trivial effect and discuss the impedance spectra in terms of the grain boundary resistivity per unit surface area of the grain boundary $\left(R_{\mathrm{sp}}\right):^{24}$

$$
R_{\mathrm{sp}}\left[\Omega \cdot \mathrm{cm}^{2}\right]=R_{\mathrm{gh}}^{\mathrm{mac}} D
$$

The average thickness $\delta_{\mathrm{gb}}$ of the grain boundary can be calculated from its capacitance $C_{\mathrm{g} b}$ using Eq. (2): ${ }^{21}$

$$
\delta_{\mathrm{gh}}=\varepsilon_{\mathrm{s}} \varepsilon_{\mathrm{r}} D / C_{\mathrm{gb}}
$$

where $\varepsilon_{0}$ and $\varepsilon_{\mathrm{r}}$ are the permittivity of free space and the grain boundary material, respectively, and $D$ is the average grain size.

To calculate the thickness $\delta_{g b}$ of the grain boundary from the impedance spectra using $\mathrm{Eq}$. (2) requires an assumption regarding the value of the relative permittivity $\varepsilon_{\mathrm{r}}$ of the grain boundary. Many silica- and alumina-based glasses have dielectric constants in the range 4-8, whereas values in the range 20-30 are reported for zirconia electrolytes. ' Van Dijk and Burggraaf $^{21}$ used the single-crystal value $\left(\varepsilon_{\mathrm{r}}=70\right)$ to calculate $\delta_{\mathrm{gl}, 2}$. The permittivity of a grain boundary wetted by an amorphous silicate phase must, however, be smaller than the single-crystal value, since this value represents the permittivity of the grain interior in polycrystalline materials. To calculate $\delta_{g b}$ from the capacitances, a value of 30 has been used for $\varepsilon_{\mathrm{r}}$, but from the discussion given above it is clear that the uncertainty in the absolute value of $\delta_{g b}$ is thus largely determined by the uncertainty in the value of $\varepsilon_{\mathrm{r}}$.

\section{Results}

\section{(1) X-ray Photoelectron Spectroscopy}

(A) General: A typical example of a survey scan of a fracture surface is shown in Fig. 1. These survey scans serve as fingerprints for the chemical composition. In this diagram the photoelectron peaks of the main components $\mathrm{Zr}, \mathrm{Y}$, and $\mathrm{O}$ can be seen, plus the $\mathrm{C} 1 \mathrm{~s}$ and $\mathrm{F} I s$ photoelectron peaks. The intensity of the $\mathrm{C} 1$ s peak decreased rapidly during sputtering, while the intensity of the F1s peak decreased only slightly. Typically, the $\mathrm{F} / \mathrm{Zr}$ atomic ratio was equal to 0.2 before sputtering. The main part of the fluorine contamination is most likely introduced during ball-milling of the powder after calcination using Tefion (polytetrafluorethylene) balls. Both fluorine and carbon were measured but not included in the quantification.

For one sample, concentrations have been measured on both fracture surfaces. The detected concentrations of the investigated elements on both surfaces were identical within the accuracy of the measurement. A single fracture surface per specimen has therefore been examined during all further measurements.

(B) Y3dRegion: In Fig. 2 the Y $3 d$ region is shown before and after sputtering for $80 \mathrm{~min}$. Three components have been used for deconvolution of the Y3d region: one singlet for $\mathrm{Si} 2 s$
$(153.0 \mathrm{eV})$, one doublet for yttrium in the oxide $(157.7 \mathrm{eV})$, and one doublet for yttrium in the silicate $(158.3 \mathrm{eV}){ }^{6}$ Gaussian functions were used for deconvolution, and the splitting and integral intensity ratio of $\mathrm{Y} 3 d_{5 / 2}$ and $\mathrm{Y} 3 d_{3 / 2}$ were fixed at 2.15 $\mathrm{eV}^{6}$ and $100 / 67,{ }^{13}$ respectively. The FWHM (full width at half maximum) of all photoelectron lines has been confined to an interval of 2-2.5 eV. Deconvolution was performed using the software supplied by Kratos to the Kratos XSAM- 800 apparatus.

Before sputtering (Fig. 2a), two yttrium species are present-one in the oxide and one in the silicate-while after sputtering (Fig. 2(b)) only yttrium in the oxide is present. The intensity of the $\mathrm{Si} 2 \mathrm{~s}$ peak is very low, even before sputtering, as can be seen in Fig. 3(a). The loss of the yttrium silicate contribution to the $Y 3 d$ region manifests itself by a gradual deepening of the valley between the $3 d_{5 / 2}$ and $3 d_{3 / 2}$ components after successive sputtering steps. Similar observations have been made by Hughes and Badwal, ${ }^{6}$ who performed XPS measurements on the free surfaces of Y-TZP materials.

(C) Si2p Region: An example of the $\mathrm{Si} 2 p$ region before sputtering can be found in Fig. 3. Double differentiation clearly showed the existence of two distinct Si species. One species has a binding energy (102-103 eV) typical for silicates, while the second species has a binding energy $(99.7 \pm 0.2 \mathrm{eV})$ more typical for covalently bonded silicon. ${ }^{13}$ With increasing sputtering time, a decrease of the ratio between the silicate and the covalent component has been observed, and finally only covalent silicon is found. A further indication for the origin of the covalent $\mathrm{Si}$ species was found in the $\mathrm{C} 1 \mathrm{~s}$ region (not shown). Again, two species were observed, one having a binding energy of 284.9 $\mathrm{eV}$ corresponding with adventitious carbon and the second having a much lower binding energy of $280.8 \mathrm{eV}$ typical for carbides. ${ }^{13}$ The covalent Si peak is most likely due to iron silicide $\left(\mathrm{Fe}_{3} \mathrm{Si}\right)$, while the carbide species can be attributed to iron carbide $\left(\mathrm{Fe}_{3} \mathrm{C}\right)$. Both chemical components originate from steel contamination introduced during the fracturing step of the samples.

Deconvolution of the $\mathrm{Si} 2 p$ region has been performed to analyze the contribution of the silicate species to the total Si signal. The following procedure has been used: (i) Gaussian line profiles were assumed, (ii) the binding energies determined from the second derivative of the spectrum were used as starting values during minimization (this was not always possible for the silicate component), (iii) the $\mathrm{BE}$ of the silicate component should be within the range $102.5-103.7 \mathrm{eV}$ typical for silicates, while the BE of the covalent silicon was confined to the interval $99.8-101.5 \mathrm{eV}$, and (iv) the FWHM of both lines should be between 1 and $3 \mathrm{eV}$.

Iron has been excluded from quantification, since the contribution to the $\mathrm{Fe} 2 p$ region of iron present in zirconia could not be distinguished from the iron present in the steel contamination.

(D) Preferential Sputtering: During destructive depth profiling by $\mathrm{Ar}^{+}$-ion bombardment compositional changes occur, commonly referred to as preferential sputtering. In oxides it is oxygen rather than the metal which is removed preferentially. Preferential sputtering of oxygen also takes place in the $Y$-TZP materials investigated here, as evidenced by a decrease of the $\mathrm{O} / \mathrm{Zr}$ atomic ratio with increasing sputtering time. This decrease is accompanied by reduction of the $\mathrm{Zr}$ signal, as evidenced by considerable broadening at the lowenergy-side of the Zr3d line observed after sputtering, caused by the appearance of reduced states like $\mathrm{Zr}^{(1)}$ and $\mathrm{Zr}^{2}+{ }^{25}$ No significant reduction of yttrium has been observed, while broadening of the $\mathrm{Si} 2 p$ peak belonging to the silicate species after sputtering also points to the formation of suboxides. Hughes ${ }^{26}$ showed using $\mathrm{Ar}^{+}$-ion sputtering (3.7 keV, flux at sample 6.6 $\mu \mathrm{A} / \mathrm{cm}^{2}$ ) that only very limited preferential sputtering of zirconium with respect to yttrium occurs in Y-TZP.

Nondestructive depth profiling by performing angle-dependent measurements is not suitable for the rough fracture surfaces investigated here. 


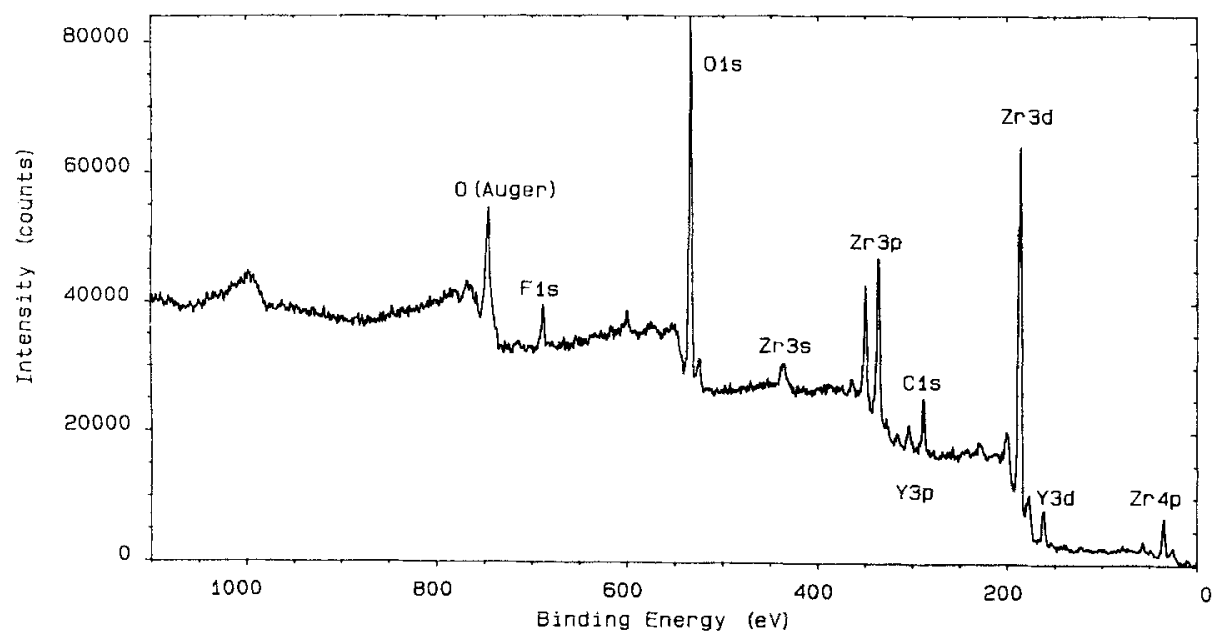

Fig. 1. Typical example of a wide scan (0-1100 eV BE) measured on a Y-TZP fracture surface (sample 1) using Mg Ka radiation.
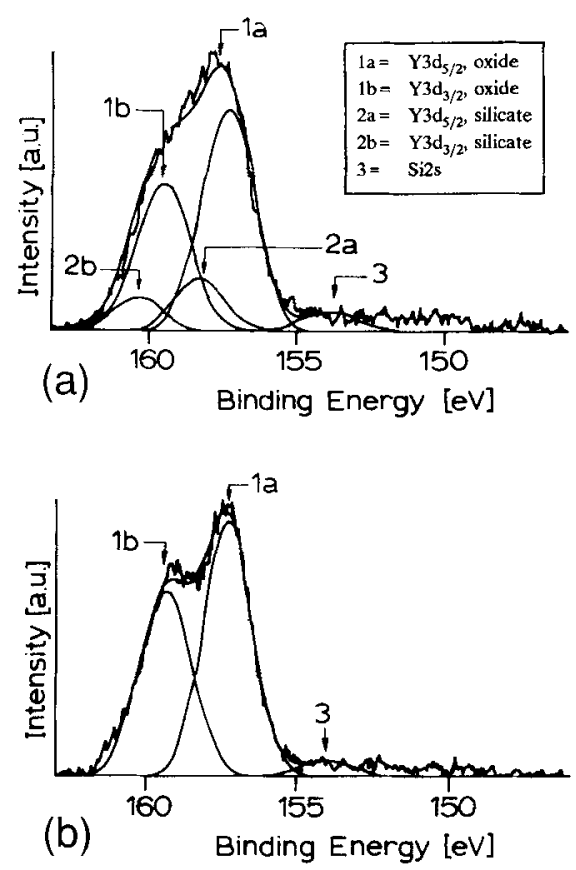

Fig. 2. Deconvolution of the $\mathrm{Y} 3 d$ region (a) before sputtering and (b) after sputtering during $80 \mathrm{~min}$.

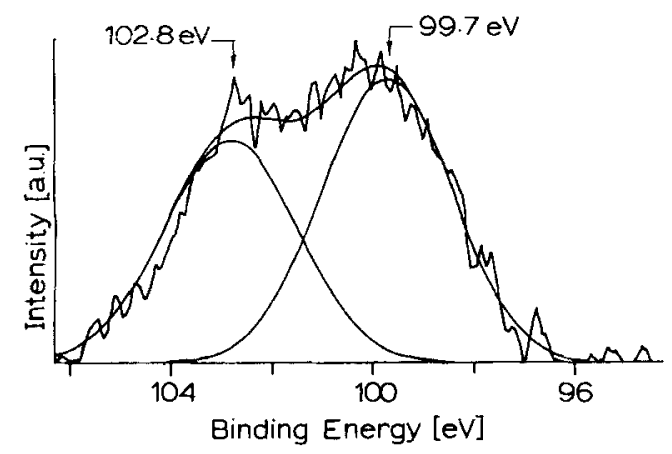

Fig. 3. Deconvolution of the $\mathrm{Si} 2 p$ region before sputtering. Two distinct species are seen, having binding energies of 102.6 and $99.8 \mathrm{eV}$.
(E) Depth Profiles after Sintering: Depth profiles of both investigated Y-TZP materials after sintering at $1150^{\circ} \mathrm{C}$ are given in Fig. 4, where atomic ratios are plotted versus sputtering time. It can be seen that the grain boundaries of both materials are enriched in yttrium compared to the bulk yttrium content ( 5 at. \%) by a factor 2.2 (Chl l, sample 2) and 2.4 (Chl2, sample 4). The steepest decrease in concentration occurs within the first $20 \mathrm{~min}$ of sputtering $(\leq 2 \mathrm{~nm}$ ) for all cations. After 80 min sputtering, the $\mathrm{Y} / \mathrm{Zr}$ ratio still has a value above that corresponding with the bulk composition. The fact that the fracture surfaces are quite rough and frequently convex prevents a good calibration between sputtering time and sputtering depth. The thickness of the segregation layer can, however, be estimated by combining XPS and SAM observations (see Section IV).

Although the Chl2 powder batch contains 3 times more silicon than batch Chll (see Table I) the $\mathrm{Si} / \mathrm{Zr}$ depth profiles are similar. The absolute values of $\mathrm{Si} / \mathrm{Zr}$ are quite low for both materials. The detected level of $\mathrm{Al}$ segregation in material $\mathrm{Chl} 1$ is $1.5-1.8$ times that of material $\mathrm{Chl} 2$, while the $\mathrm{Al}$ contents in the starting powders are very similar (see Table I). Sodium could be detected only in sample 2 and is confined to a very narrow region near the grain boundary.

(F) Depth Profiles after Superplastic Deformation: In Fig. 5, depth profiles of material Chl 1 after sintering and after compression at $1300^{\circ} \mathrm{C}$ under a low stress (20 MPa) are given. After deformation, the yttrium content of the grain boundary

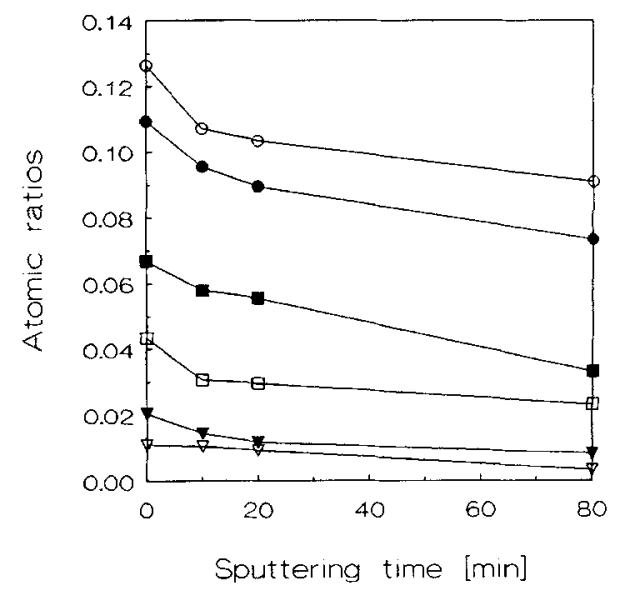

Fig. 4. Depth profile of samples after sintering at $1150^{\circ} \mathrm{C}$ : filled symbols: sample 2, Chl1; open symbols: sample 4, Chl2; circles: $\mathrm{Y} / \mathrm{Zr}$; squares: $\mathrm{Al} / \mathrm{Zr}$; triangles: $\mathrm{Si} / \mathrm{Zr}$. 
remains unchanged, but a steeper decrease with sputtering time is observed. Curve fitting of the $\mathrm{Y} 3 d$ region reveals that the contributions of the silicate component to the total Y $3 d$ signal before sputtering are comparable before and after compression. Aluminum has segregated to a slightly higher value, but like yttrium the signal decreases more rapidly during sputtering compared to the sintered sample. The depth profiles of silicon are quite similar in both samples.

In Fig. 6, depth profiles measured on $\mathrm{Chl} 2$ samples are shown. One sintered sample (No. 4) is compared to two deformed samples. Compression took place at $1250^{\circ} \mathrm{C}$ under 20 $\mathrm{MPa}$ (No. 5) and at $1100^{\circ}-1200^{\circ} \mathrm{C}$ under 20-120 MPa (No. 6). A significant decrease in yttrium concentration at the fracture surface is observed in the deformed samples, the largest decrease being observed in sample 6 , which was subjected to a much higher stress than sample 5. Deconvolution of the $\mathrm{Y} 3 d$ region revealed a strong decrease of the yttrium silicate component in the deformed samples. Aluminum content of the grain boundaries has decreased slightly after deformation, while the silicon content before sputtering remains unchanged. The silicon concentration decreases very rapidly with sputtering time in sample 6, which also showed the largest decrease in yttrium content. Sodium could be detected only in sample 5 ; a Na/Zr ratio equal to 0.01 was found at the grain boundary. Most of the sodium was removed during the first $20 \mathrm{~min}$ of sputtering.

\section{(2) Scanning Auger Microscopy}

As mentioned in Section II(4), only in the case of the sintered samples (before sputtering) has an estimate been made of the $\mathrm{Y} / \mathrm{Zr}$ ratio using SAM. The information depth of the $\mathrm{Y} M N N$

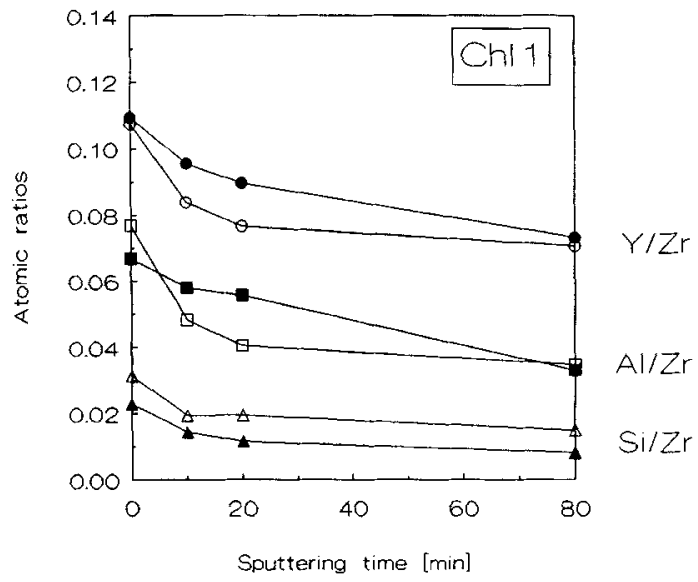

Fig. 5. Depth profiles of material Chl 1 before and after compression: sintered sample 2 (filled symbols) and compressed sample 3 (open symbols).

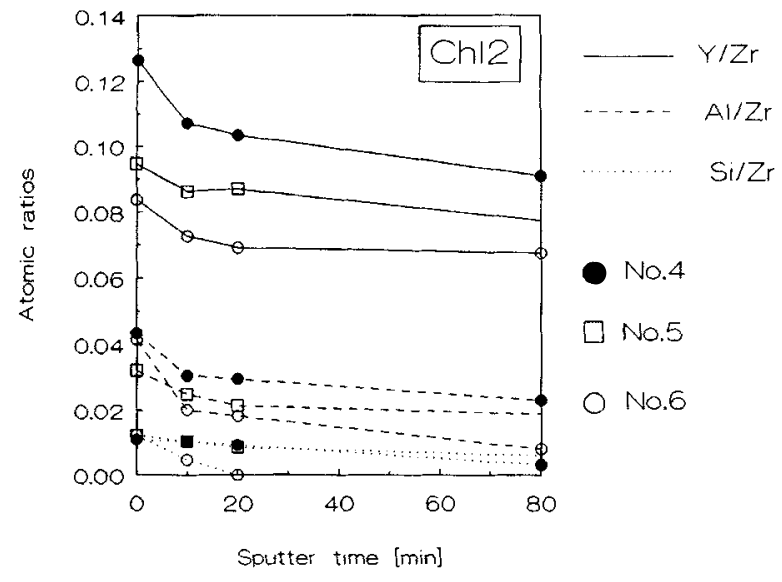

Fig. 6. Depth profiles of one sintered Chl2 sample (No. 4) and two compressed samples (5 and 6 ). and Zr MNN Auger electrons equals 1.9 and $2.3 \mathrm{~nm}$, respectively. The depth resolution of this analysis is enhanced by a factor of 3 compared with the XPS-analysis (Section II(2)), where the $\mathrm{Y} 3 d$ and $\mathrm{Zr} 3 d$ photoelectrons with kinetic energies $>1000 \mathrm{eV}$ are used. For both Y-TZP materials, a Y/Zr ratio equal to 0.3 has been found at the grain boundary. This indicates the existence of a very thin (1-2 nm) yttrium-rich layer at the grain boundaries.

\section{(3) Transmission Electron Microscopy}

In Fig. 7, a bright-field image of an ultrathin intergranular amorphous film in the as-sintered material is shown as observed by the Fresnel fringe imaging technique. A continuous film having a thickness of less than $1 \mathrm{~nm}$ is observed at all examined grain boundaries after sintering. However, given the limited number of observations, it cannot be ruled out that some lowangle grain boundaries are not covered by the amorphous phase.

In a sample deformed under low stress (Chl2, No. 5), both grain boundaries devoid of any amorphous film as well as grain boundaries still covered by a thin amorphous film have been observed. This demonstrates that partial dewetting has taken place during compressive deformation. Figure 8 shows a highresolution image of an area where lattice fringes can be followed to their intersections at a two-grain junction, indicating the absence of any amorphous phase. Preliminary results of EDS microanalysis indicate that "clean" grain boundaries do not possess an enrichment in yttrium compared to the grain interior. A certain fraction of the grain boundaries (sample No. 5) are still wetted by an amorphous film. The thickness of this film equals $1 \mathrm{~nm}$. EDS microanalysis (spot size $2.5 \mathrm{~nm}$ ) showed that these wetted grain boundaries are enriched in yttrium by a factor of 2 compared with the grain interior, as illustrated in Fig. 9. Segregation of yttrium thus only seems to take place at those grain boundaries covered by the amorphous silicate layer. The dewetting process should therefore lead to a decrease of the average yttrium grain boundary concentration, as has indeed observed by XPS.

\section{(4) Impedance Spectroscopy}

In Fig. 10, the impedance spectra (recorded at $341^{\circ} \mathrm{C}$ ) are shown of material Chl4 after sintering at $1150^{\circ} \mathrm{C}(10 \mathrm{~h})$ and after subsequent compression to 0.5 true strain at $1250^{\circ} \mathrm{C}$ under initial stresses of 20,60 , and $100 \mathrm{MPa}$. Average grain sizes are in the range $0.21-0.24 \mu \mathrm{m}$. It can be seen in Fig. 10 that the grain boundary resistivity decreases strongly after compression at $1250^{\circ} \mathrm{C}$, whereas this thermomechanical treatment leaves the lattice resistivity almost unchanged. This decrease of the grain boundary resistivity becomes stronger with increasing applied stress, as can be seen more clearly in Fig. 11 , where $R_{\mathrm{sp}}$ is plotted versus the applied initial stress.

Part of the decrease in $R_{\mathrm{sp}}$ after compressive deformation might be due to the effect of temperature alone. In order to be able to separate the effect of temperature and compressive deformation, $\mathrm{Ch} 14$ samples have been annealed at $1250^{\circ} \mathrm{C}$ during various times without being compressed. Figure 12 shows the evolution of $R_{\mathrm{sp}}$ with time for annealed and compressed samples. The specific grain boundary resistivity of annealed samples increased initially with increasing annealing time (up to $120 \mathrm{~min}$ ) and was larger by a factor 1.3 to 2.0 compared to the deformed ones. Prolonged pressureless annealing $(3 \mathrm{~h}$ or more) led to a strong decrease of $R_{\mathrm{sp}}$ to a level comparable to the deformed materials. More details concerning the electrical characteristics of grain boundaries in $\mathrm{Y}-\mathrm{TZP}$, pressureless annealed at various temperatures are given elsewhere. ${ }^{22}$

A value of $1.9 \mathrm{~nm}$ has been found using Eq. (2) for $\delta_{\mathrm{gb}}$ after sintering at $1150^{\circ} \mathrm{C}$, which is in fairly good agreement with the thickness $(1 \mathrm{~nm})$ of the silicate phase observed by TEM. The average thickness of the grain boundaries as calculated from the capacitances for samples compressed at $1250^{\circ} \mathrm{C}$ decreased from $2.1 \mathrm{~nm}$ for the sample compressed under $20 \mathrm{MPa}$ to 1.8 $\mathrm{nm}$ for the sample compressed under $100 \mathrm{MPa}$. The grain boundary thickness of the pressureless annealed samples 


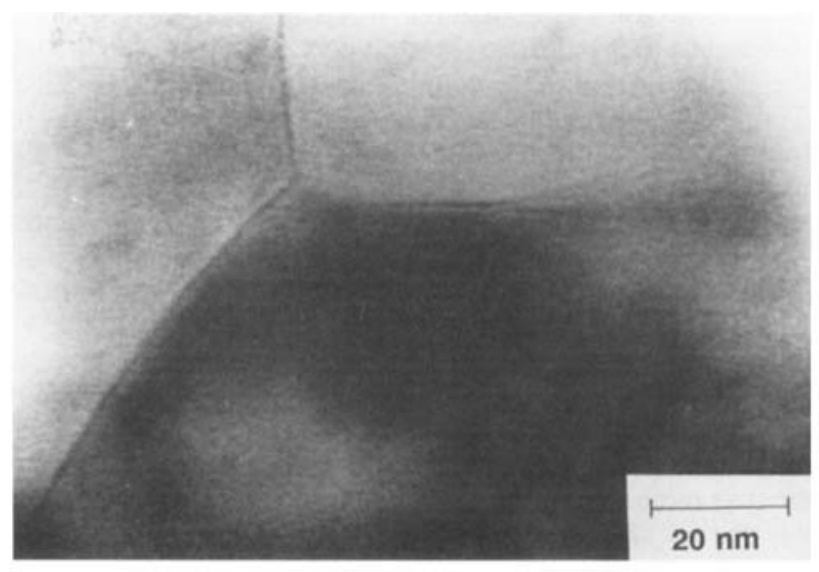

(a)

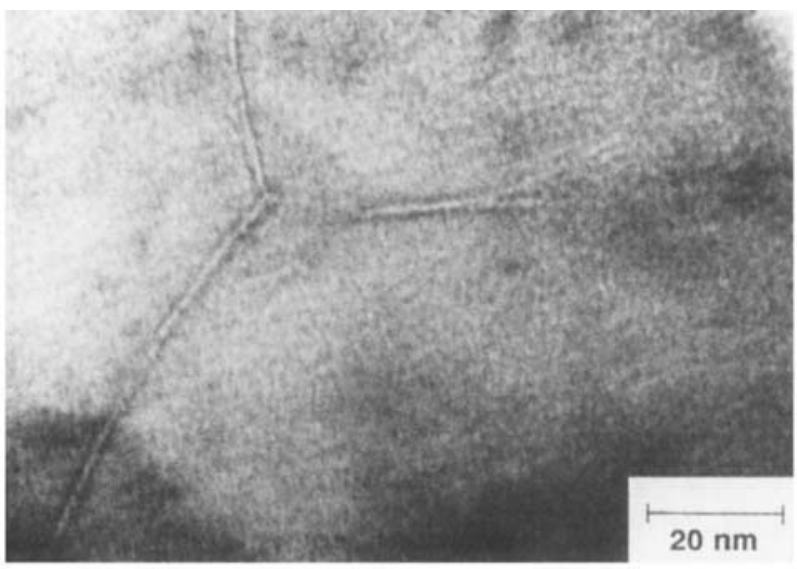

(b)

Fig. 7. Bright-field image of an intergranular amorphous phase in the as-sintered material observed by the Fresnel imaging technique: (a) overfocus conditions, (b) underfocus conditions. (Courtesy T. Stoto, EPF Lausanne, Switzerland.)

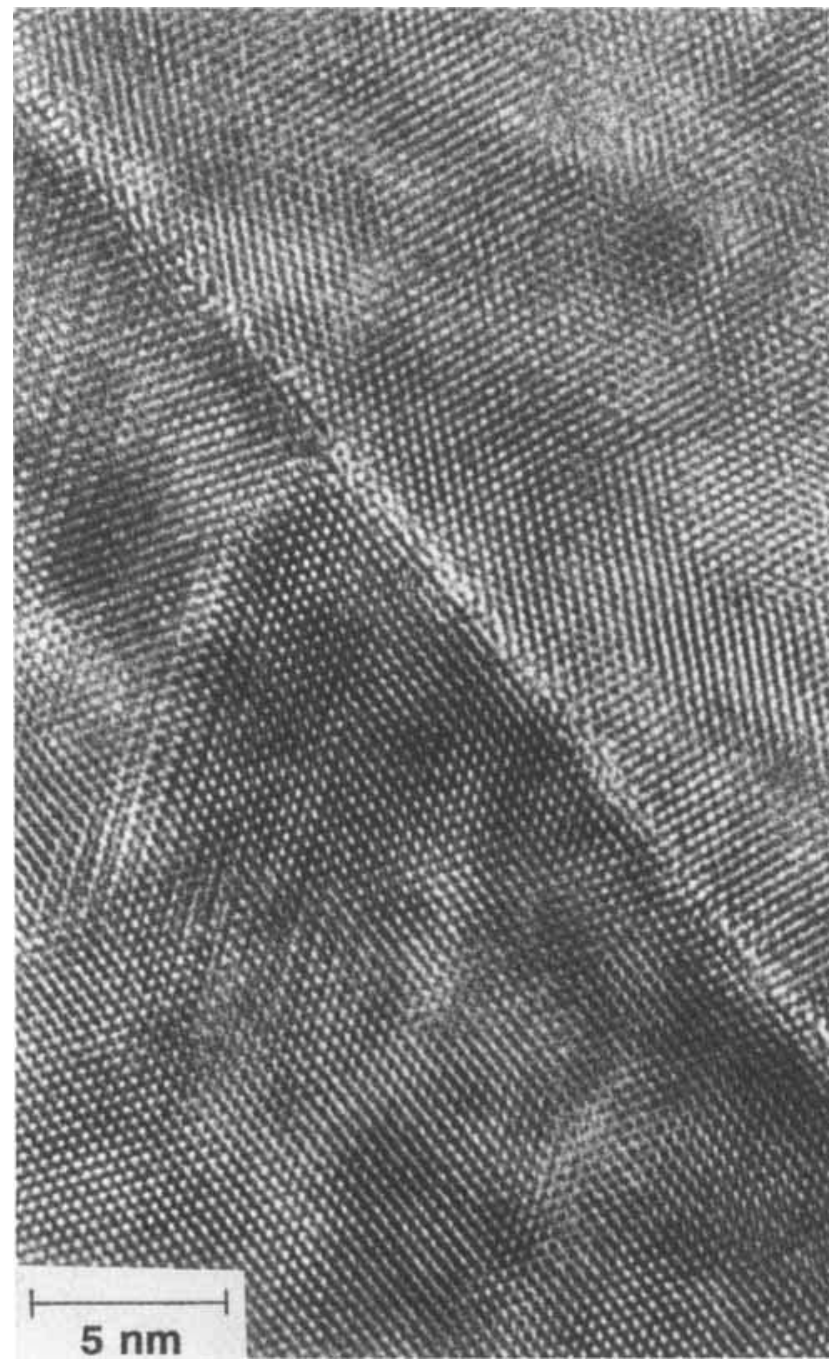

Fig. 8. High-resolution image of a grain boundary devoid of any amorphous phase (Ch12, sample 5).

increased from $2.5 \mathrm{~nm}$ (15-min dwell) to $4.5 \mathrm{~nm}$ (120-min dwell). After prolonged annealing ( $3 \mathrm{~h}$ or more), $\delta_{\mathrm{gb}}$ decreased again to a value near $2 \mathrm{~nm}$.

The impedance analysis of the Ch14 material confirms that important changes in the grain boundary chemistry are taking

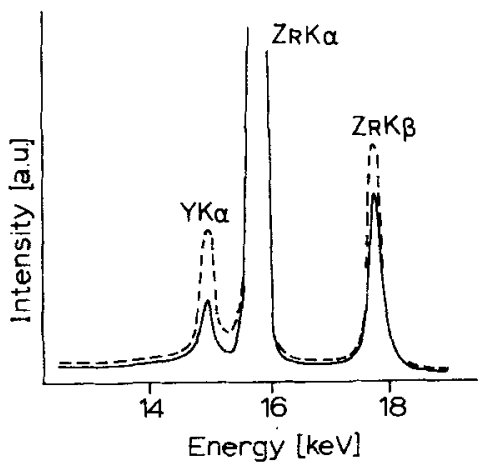

Fig. 9. EDS spectra of grain interior and a wetted grain boundary (Chl2, sample 5), illustrating the yttrium enrichment of wetted grain boundaries. Dashed line: grain boundary; solid line: grain interior.

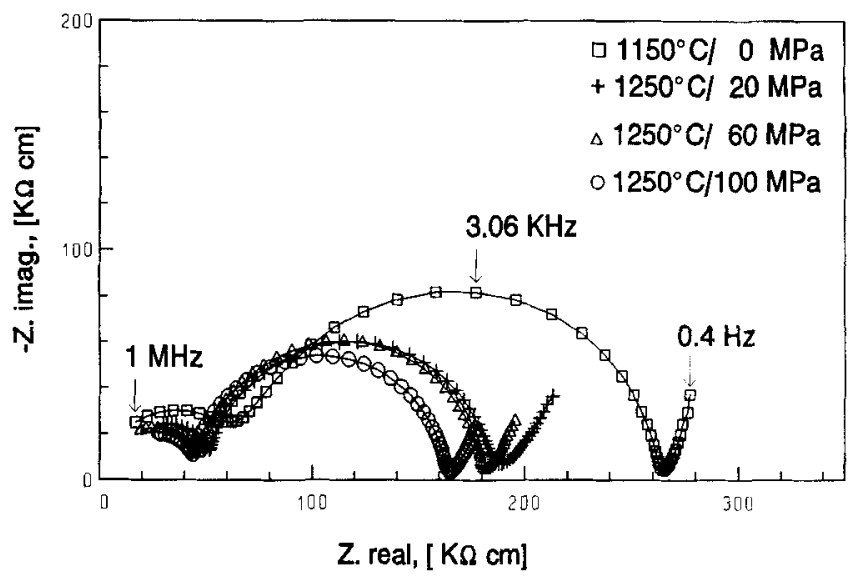

Fig. 10. Impedance spectra, measured at $341^{\circ} \mathrm{C}$ in air, of Chl4 samples (No. $7-10)$, sintered at $1150^{\circ} \mathrm{C}(10 \mathrm{~h})$ or compressed at $1250^{\circ} \mathrm{C}$ to 0.5 true strain under initial stresses of 20,60 , and $100 \mathrm{MPa}$. Three examples of the frequencies used for the analysis are indicated.

place during the investigated thermomechanical treatments, as will be further discussed in Section IV.

\section{Discussion}

\section{(1) Grain Boundary Segregation of Yttrium}

The segregation of yttrium to the external surfaces of Y-TZP materials has been investigated by several researchers. 


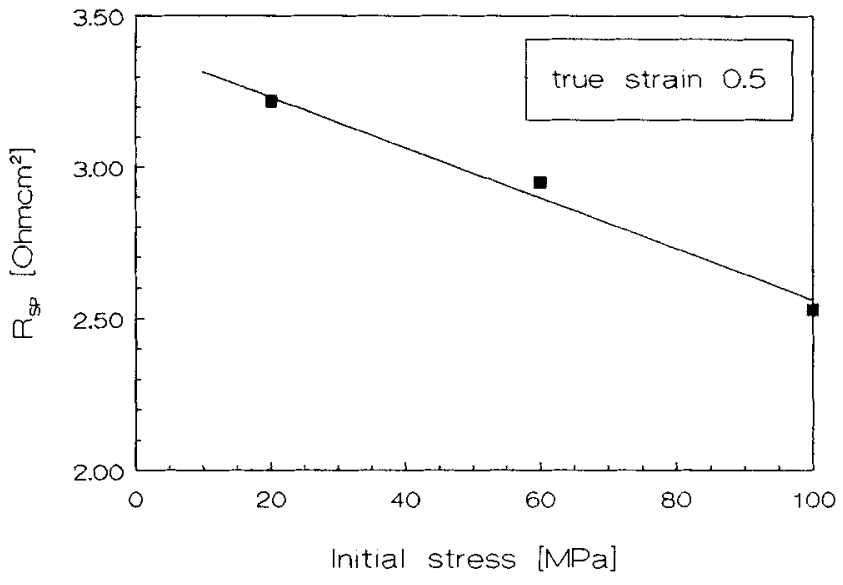

Fig. 11. The grain boundary resistivity per unit grain boundary surface area $\left(R_{\mathrm{sp}}\right)$ as a function of applied stress of the Ch14 samples. After sintering, $R_{\mathrm{s}}$ equals $4.1 \Omega \cdot \mathrm{cm}^{2}$.

\section{- annealed - deformed}

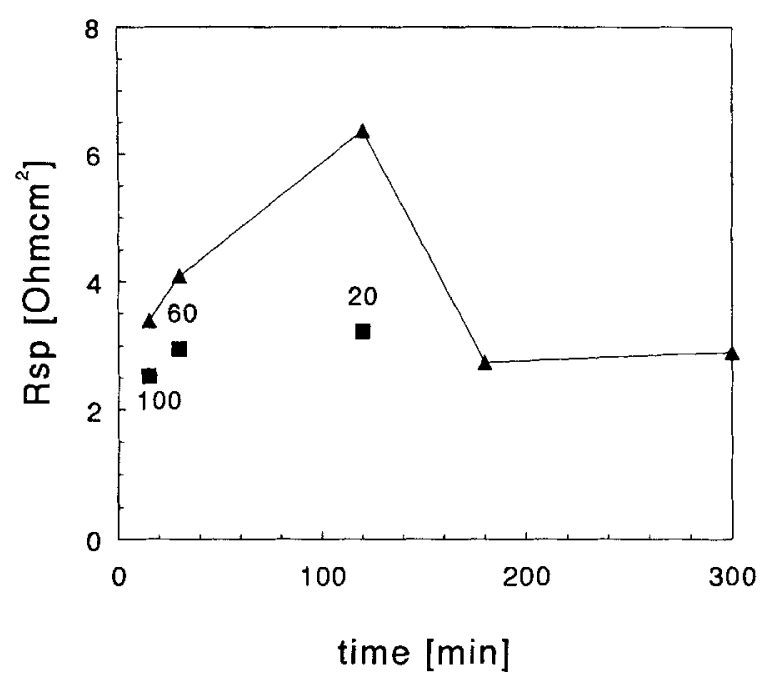

Fig. 12. Evolution of $R_{\mathrm{vp}}$ with time for the Chl4 material during pressureless annealing or compression to 0.5 true strain (under 20,60 , and $100 \mathrm{MPa}$ at $1250^{\circ} \mathrm{C}$.

Theunissen et al..$^{27}$ measured a surface concentration of 31 at.\% after heat treatment at $1000^{\circ} \mathrm{C}$ by AES, while XPS measurements yielded a surface concentration of 28 at. \%. Hughes and Badwal $^{6}$ observed peak values in the $\mathrm{Y} / \mathrm{Zr}$ ratio of $0.17-0.20$ (corresponding with 15-17 at.\% yttrium) by XPS in two types of 3Y-TZP materials. Nieh et al. ${ }^{28}$ measured the yttrium concentration by XPS at the intergranular fracture surface of $\mathrm{Y}$-TZP. After superplastic elongation at $1650^{\circ} \mathrm{C}$, he found an $\mathrm{Y} /$ $\mathrm{Zr}$ ratio equal to 0.11 ( $\equiv 10 \mathrm{at} . \%$ yttrium). In cubic zirconiayttria (stabilized with 17 at.\% yttrium), segregation of yttrium to the grain boundaries and free surfaces has been analyzed using AES by, respectively, Winnubst et al. ${ }^{19}$ and Burggraaf et $a .^{29}$ The yttrium concentration at the grain boundary equaled 25 at $\%$ after sintering at $1180^{\circ} \mathrm{C}$, while the surface concentration equaled $35 \mathrm{at} \%$ after heat treatment at $1000^{\circ} \mathrm{C}$.

The $\mathrm{Y} / \mathrm{Zr}$ ratios at the grain boundaries in the as-sintered materials analyzed by XPS (Section III(1)(E)) are close to the value given by Nieh. SAM measurements demonstrated that, after sintering, the outermost 2-nm-thick layer has an $\mathrm{Y} / \mathrm{Zr}$ ratio equal to 0.3 . TEM observations showed the existence of a 1 -nm-thick amorphous film at the grain boundaries. This silicate film is thus strongly enriched in yttrium. From the information depths of the XPS and SAM analyses (6 and $2 \mathrm{~nm})$ and the
Y/Zr ratios of the as-sintered materials obtained with these techniques ( 0.3 and 0.11 , respectively), it can be calculated that the $\mathrm{Y} / \mathrm{Zr}$ ratio within the volume lying at a depth between 2 and $6 \mathrm{~nm}$ below the fracture surface is close to the bulk value $(0.05)$. It can therefore be concluded that yttrium enrichment takes place only in the outermost $2 \mathrm{~nm}$ of the grain boundaries. The statistical thickness of the glassy film at an intergranular fracture surface is $0.5 \mathrm{~nm}$, and any yttrium enrichment in the zirconia grains themselves is thus confined to a layer with a thickness of $1.5 \mathrm{~nm}$ at the grain boundaries. Deconvolution of the Y3d region gives the atomic ratio between yttrium present in the silicate film and yttrium present in the oxide. The concentration of zirconium in the silicate film is quite low, ${ }^{5,30}$ and this allows one to determine the $\mathrm{Y} / \mathrm{Zr}$ atomic ratio in the zirconia grains from the deconvolution of the $\mathrm{Y} 3 d$ region. It can be concluded from the data of the as-sintered materials that yttrium enrichment does occur in the outermost layer with a thickness of $1.5 \mathrm{~nm}$ mentioned above. The yttrium enrichment observed at grain boundaries wetted by a glassy film is thus not confined to the glassy film alone.

Recently, it has been found that the defocus Fresnel fringe method overestimates the thickness of intergranular films by $20 \%-35 \% .^{31}$ The thickness of $1 \mathrm{~nm}$, reported here for the intergranular film, must thus be considered as an upper limit. The conclusion just given, concerning the yttrium enrichment of grain boundaries beneath the glassy film, remains, however, unaffected by this uncertainty in the thickness.

The discrepancies between the segregation levels reported for yttrium by different authors can be readily explained. First of all, segregation levels at the free surfaces are in general somewhat higher than those at the grain boundaries. More important, however, in the case of zirconia is the presence or absence at the free surfaces or grain boundaries of an amorphous silicate film and its thickness. The solubility of yttrium in this film depends strongly on the type of silicate. ${ }^{32,33}$ The amorphous grain boundary phase in zirconia is generally an aluminosilicate, and the yttrium solubility in this phase is quite appreciable. ${ }^{32}$ The ratio of the thickness of the glassy film and the information depth of the analysis method used is another important factor. Suppose the thickness of the aluminosilicate film increases during a particular thermal treatment: this will lead to an increase of the $\mathrm{Y} / \mathrm{Zr}$ ratio until the thickness exceeds the information depth of the analysis method.

\section{(2) Formation and Dewetting of the Amorphous Film}

The amorphous phase in Y-TZP materials is rich in Si and Y and contains $\mathrm{Al}$ as a third main component. It is often stated ${ }^{4,5}$ that the glassy phase in commercial Y-TZP materials, sintered at temperatures of $1400^{\circ} \mathrm{C}$ or more, corresponds with a eutectic liquid in the yttria-alumina-silica system. The formation of an amorphous silicate phase at $1150^{\circ} \mathrm{C}$ as observed in the $\mathrm{Chl}$ materials cannot be attributed to any (equilibrium) eutectic in this ternary system, because the lowest eutectic temperature in this system is $1335^{\circ} \mathrm{C} .{ }^{34}$ The presence of fluorine in the grain boundary phase of the Chl materials might be responsible for the formation of a eutectic at very low temperature, since it is well-known that fluorine can lead to a strong lowering of the liquidus in silicate systems..$^{35,36}$

The picture which emerges from the combination of XPS, TEM, SAM, and IS observations is that after sintering (at $1150^{\circ} \mathrm{C}$ ) most of the grain boundaries of the $\mathrm{Chl}$ materials are wetted by a continuous film of an amorphous materialpresumably liquidlike at the sintering temperature-and that dewetting occurs during high-temperature $\left(1200^{\circ}-1300^{\circ} \mathrm{C}\right)$ compressive deformation. TEM observations showed that, after deformation under low stress (20 MPa), certain grain boundaries remain wetted by an amorphous film. Because the materials deform via grain boundary sliding - a mechanism involving both grain translation and rotation ${ }^{37}$-all grain boundaries experience a compressive stress at some stage during deformation to 0.5 true strain. It is therefore the relative misorientation of grain boundaries that determines which boundaries will 
dewet first (see below). The degree of dewetting is expected to increase with increasing applied stress. Impedance spectroscopy showed that the decrease of the specific grain boundary resistivity due to compression at $1250^{\circ} \mathrm{C}$ is proportional to the applied stress. Progressive removal of the poorly conducting silicate phase from the grain boundaries, leading to an increasing fraction of "clean" grain boundaries, is consistent with this observation. Badwal et al. ${ }^{8}$ observed a similar trend for the grain boundary resistivity of $\mathrm{Y}-\mathrm{TZP}$ during compression at $1200^{\circ} \mathrm{C}$ under $10-100 \mathrm{MPa}$.

EDS analysis performed on thin foils of a deformed material indicated that segregation of yttrium occurs only at grain boundaries wetted by an amorphous film, in good agreement with TEM/EDS observations reported by Stoto et al. ${ }^{5}$ Dewetting should therefore lead to a decrease of the average yttrium concentration of the grain boundaries. This has indeed been observed with XPS for especially the Chl2 material (see Section III (1)(F)).

Summarizing, two types of grain boundaries have been observed in the Y-TZP materials deformed at low stress: (type 1) "clean" grain boundaries, not wetted by an amorphous film, which are not enriched in yttrium compared to the grain interior, and (type 2) grain boundaries wetted by an amorphous film, which show an enrichment in yttrium that is not confined to the glassy film alone. We have not yet studied the crystallographic nature of the different grain boundaries, but most probably type 1 grain boundaries are low-angle grain boundaries or grain boundaries with a "special" orientation (see below), and type 2 grain boundaries are high-angle grain boundaries. The dewetting model of Clarke ${ }^{38}$ predicts that most of the type 1 grain boundaries should already be "clean" before compressive deformation. The low sintering temperature $\left(1150^{\circ} \mathrm{C}\right)$ of the $\mathrm{Chl}$ materials makes this even more likely. XPS analysis has shown that, even after deformation under $120 \mathrm{MPa}$, the grain boundaries are slightly enriched in yttrium. This suggests that, even after removal of the amorphous film, type 2 grain boundaries remain enriched in yttrium.

Upon dewetting, the amorphous film may contract into pockets at multiple-grain junctions. Alternatively, impurities can migrate to the external surface, leaving a clean grain boundary behind. Hughes and Badwal have found evidence, using XPS and IS, for the latter process to occur during pressureless annealing of both tetragonal ${ }^{6}$ and cubic $^{39}$ yttria-stabilized zirconia. The presence of fluorine in the grain boundary phase of the Chl materials as found by XPS might facilitate its migration to the external surface or to pockets at multiple-grain junctions, since fluorine is known to lead to high fluidity of oxide glasses. ${ }^{40}$

Dewetting can occur due to the combined effect of temperature and pressure. At temperatures above that used for sintering, the composition of the silicate phase present at the grain boundaries will change due to changing segregation levels of the various impurities, and wetting might be no longer energetically favorable for certain grain boundary orientations. This scenario seems quite compatible with the evolution of $R_{\mathrm{sp}}$ with time during pressureless annealing at $1250^{\circ} \mathrm{C}$ (Fig. 12). Initially, $R_{\mathrm{sp}}$ increases due to enhanced segregation of impurities, and this change of composition then leads to spontaneous dewetting accompanied by a strong decrease of $R_{\mathrm{sp}}$. During the time used for deformation to 0.5 true strain (ranging from $15 \mathrm{~min}$ under $100 \mathrm{MPa}$ to $120 \mathrm{~min}$ under $20 \mathrm{MPa}$ ) at this temperature, dewetting does not take place spontaneously, but is induced by the applied stress.

Clarke $^{41}$ has formulated a force balance for a thin intergranular liquid silicate film. Without applying an external pressure, the equilibrium thickness is of the order of a few nanometers and is determined by the balance between attractive van der Waals forces and a repulsive force, finding its origin in an epitaxial orientation of the $\mathrm{SiO}_{4}$ tetrahedra with the grain's surfaces. Inserting the appropriate numerical values for the different parameters in Clarke's force balance shows that a compressive stress of $40 \mathrm{MPa}$ is required to remove a liquid silicate film at elevated temperatures from $\mathrm{ZrO}_{2}$-liquid- $\mathrm{ZrO}_{2}$ boundaries. Considering the large number of simplifications in Clarke's theory, this value is in good agreement with the minimum stress of $20 \mathrm{MPa}$, where dewetting was observed in this investigation.

The earlier model of Clarke ${ }^{38}$ provides an intuitive explanation for the partial dewetting, the degree of which increases with increasing applied stress, as observed in this investigation. The relative misorientation of wetted grain boundaries will determine which boundaries will dewet first during compressive deformation. Those boundaries possessing a crystalcrystal energy $\left(\gamma_{\mathrm{ss}}\right)$ only slightly larger than the energy of the wetted boundary $\left(2 \gamma_{\mathrm{s}}\right)$ will dewet first, i.e., at low stresses. Higher stresses will be required for those boundaries for which the energy difference $\gamma_{\mathrm{ss}}-2 \gamma_{\mathrm{st}}$ is larger.

Work hardening observed during creep of the investigated materials as described in Ref. 11 can most likely be attributed to the progressive dewetting of the grain boundaries as discussed above, since the grain size was quite stable during deformation. Silicon concentrations at the grain boundaries as found by XPS are quite low, although the starting powders contain $300-1100$ ppm silicon. It can be speculated that part of the silicon is removed from the grain boundaries by the formation of the volatile $\mathrm{SiF}_{4}$ compound.

\section{Conclusions}

(a) After sintering at $1150^{\circ} \mathrm{C}$, grain boundaries in Y-TZP materials prepared via the "chloride" route are wetted by a thin ( $\leq 1 \mathrm{~nm}$ ) amorphous film. This film is rich in yttrium and contains aluminum, silicon and fluorine as further main components. The outermost layer with a thickness of $1.5 \mathrm{~nm}$ of the zirconia grains themselves (beneath the glassy film) in the assintered material is also enriched in yttrium.

(b) After deformation of 0.5 true strain at $1250^{\circ} \mathrm{C}$ under 20 $\mathrm{MPa}$, some grain boundaries are no longer covered by an amorphous film, and no yttrium segregation to these clean grain boundaries has been observed by EDS.

(c) Both XPS and IS measurements indicate that the extent of dewetting increases with increasing applied stress during deformation to 0.5 true strain at $1200^{\circ}-1300^{\circ} \mathrm{C}$.

(d) Cleaning of grain boundaries must occur by the escape of impurities to the external surface or to pockets at multiplegrain junctions in the investigated deformed Y-TZP materials. The presence of fluorine in the amorphous phase will facilitate this process, since it is known to lead to high fluidity of oxide glasses.

Acknowledgments: Albert van den Berg of the Center for Materials Research at the University of Twente is acknowledyed for pertorming XPS and SAM measurements, Dr. Tiziana Stoto (EPF Lausanne, Switzerland) and Dr. J. Beyer for TEM observations, René Olde Scholtenhuis for assistance with creep tests; and Hans Weber for impurity analysis.

\section{References}

${ }^{\prime}$ S. P. S. Badwal, J. Drennan, and A. E. Hughes, "Segregation in Oxygen-Ion Conducting Electrolytes and Its Influence on Electrical Properties"; pp. 227-85 in Science of Ceramic Interfaces. Edited by J. Nowotny. Elscvier Science Publishers, Amsterdam, Netherlands, 1991.

C. Carry, "Microstructures, Grain Boundaries and Superplasticity in Fine Grained Ceramics"; pp. 313-23 in Superplasticity in Metals. Ceramics and Intermetallics, MRS symposium proceedings, Vol. 196. Edited by M. J. Mayo, M. Kobayashi, and J. Wadsworth. Materials Research Society, Pittsburgh, PA. 1990.

${ }^{3}$ Y. Yoshizawa and T. Sakuma, "Role of Grain-Boundary Glass Phase on the Superplastic Deformation of Tetragonal Zirconia Polycrystal," I. Am. Ceram. Soc, 73 [10] 3069-73 (1990).

${ }^{+} M$. Ruhle, N. Claussen, and A. H. Heuer. "Microstructural Studies of $\mathrm{Y}_{2} \mathrm{O}_{3}$-Containing Tetragonal $\mathrm{ZrO}_{2}$ Polycrystals (Y-TZP)"; pp. 352-70 in Advances in Ceramics, Vol. 12, Science and Technology of Zirconia II. Edited by N. Claussen, M. Rühle, and A. H. Heuer. American Ceramic Society, Columbus, $\mathrm{OH}, 1984$.

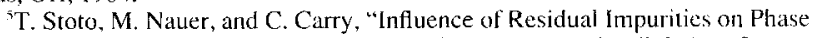
Partitioning and Grain Growth Processes of Y-TZP Materials," J. Am. Ceram. Soc., 74 [10] 2615-21 (1991).

A. E. Hughes and S. P. S. Badwal, "Impurity and Yttrium Segregation in Ytria-Tetragonal Zirconia," Soltd State Ionits, 46, 265-74 (1991). 
${ }^{7}$ S. P. S. Badwal and J. Drennan, "Grain Boundary Resistivity in Y-TZP Materials as a Function of Thermal History," J. Mater. Sci., 24, 88-96 (1989).

${ }^{8}$ S. P. S. Badwal, F. T. Ciacchi, M. V. Swain, and V. Zelizko, "Creep Deformation and the Grain-Boundary Resistivify of Tetragonal Zirconia Polycrystalline Materials," J. Am. Ceram. Soc., 73 [8] 2505-507 (1990).

${ }^{\circ} \mathrm{M}$. Nauer and C. Carry, "Flow Behaviors at High Temperature of Yttria Doped Zirconia Polycrystals"; pp. 323-28 in Euro-Ceramics, Vol. 3. Edited by G. de With, R. A. Terpstra, and R. Metselaar. Elsevier Applied Science, London and New York, 1989

${ }^{10} \mathrm{C} . \mathrm{J}$. Hwang and I-W. Chen, "Effect of a Liquid Phase on Superplasticity of 2-mol\%- $\mathrm{Y}_{2} \mathrm{O}_{3}$-Stabilized Tetragonal Zirconia Polycrystals," J. Am. Ceram. Soc., $73[6] 1626-32(1990)$

"M. M. R. Boutz, A.J. A. Winnubst, A. J Burggraat, M. Nauer, and C. Carry, "Low Temperature Superplastic Flow of Yttria Stabilized Tetragonal Zirconia Polycrystals," J. Eur. Ceram. Soc., 13 [2] 103-1] (1994).

${ }^{12}$ W. F. M. Groot Zevert, A. J. A. Winnubst, G. S. A. M. Theunissen, and A. J. Burggraaf, "Powder Preparation and Compaction Behaviour of Fine-Grained Y-TZP," I. Mater. Sci., 25, 3449-55 (1990).

1.3. Briggs and M. P. Seah, Practical Siafface Aralysis, ist ed. Wiley, Chichester, U.K., 1983.

${ }^{14}$ D. A. Shirley, "High-Resolution X-ray Photoemission Spectrum of the Valence Bands of Gold," Phys. Rev. B: Condens. Matter, 5 [4] 4709-14 (1972).

${ }^{15}$ C. D. Wagner, L. E. Davis, M. V. Zeller, J. A. Taylor, R. H. Raymond, and L. H. Gale, Surf. Interface Anal., 3, 211 (1981). Reproduced as "Appendix 5 Empirically Derived Atomic Sensitivity Factors for XPS"; p. 511-14 in Practical Surface Analysis by Auger and X-ray Photoelectron Spectroscopy. Edited by D. Briggs and P. Seah. Wiley, Chichester, U.K., 1983.

${ }^{1 M}$ M. P. Seah and W. A. Dench, "Quantifative Electron Spectroscopy of Surfaces: A Standard Data Base for Electron Inelastic Mean Free Paths in Solids," Surf. Interface Anal., 1 [1] 2-11 (1979).

${ }^{7}$ D. R. Clarke, "On the Detection of Thin Intergranular Films by Electron Microscopy," Ultramicroscopy, 4, 33-44 (1979).

${ }^{1 \times}$ L. E. Davis, N. C. McDonald, P. W. Palmberg, G. E. Riach, and R. E. Weber, Handhook of Auger Spectroscopy, 2nd ed. Physical Electronics, Edina, MN, 1978

${ }^{1 y}$ A. J. A. Winnubst, P. J. M. Kroot, and A. J. Burggraaf, "AES/STEM Grain Boundary Analysis of Stabilized Zirconia Ceramics," J. Phys. Chem. Solids, 44 [10| 955-60 (1983).

${ }^{20} \mathrm{~J}$. R. McDonald and W. B. Johnson, "Fundamentals of Impedance Spectroscopy"; pp. 1-20 in Impedance Spectroscopy. Edited by J. R. McDonald. Wiley, New York, 1987.

${ }^{21}$ T. van Dijk and A. J. Burggraaf, "Grain Boundary Effects on Ionic Conductivity in Ceramic Gd $\mathrm{Zr}_{1}, \mathrm{O}_{2 \ldots, 2}$ Solid Solutions," Phys. Status Solidi A, 63, $229-40(1981)$.

${ }^{22}$ C. S. Chen, M. M. R. Boutz, A. J. A. Winnubst, B. A. Boukamp, and A. J. Burggraaf, "The Electrical Characterization of Grain Boundaries in Ultra-Fine Grained Y-TZP," Mater. Sci. Eng., A, 168, 231-34 (1993).

${ }^{23}$ M. J. Verkerk, B, J. Middelhuis, and A. J. Burggraaf, "The Effect of Grain Boundaries on the Conductivity of High-Purity $\mathrm{ZrO}_{2}-\mathrm{Y}_{2} \mathrm{O}_{3}$ Ceramics," Solid State lonics, 6, 159-70 (1982)

${ }^{24} \mathrm{M}$. Miyayama and H. Yanagida, "Dependence of Grain-Boundary Resistivity on Grain-Boundary Density in Yttria Stabilized Zirconia,". I. Am. Ceram. Soc., 67, C-194-C-195 (1984).
${ }^{25}$ R. Kaufman, H. Klewe-Nebenius, H. Moers, G. Pfennig, H. Jenett, and H. J. Ache, "XPS Studies of the Thermal Behaviour of Passivated Zircaloy-4 Surfaces," SIA, Surf. Interface Anal., 11, 502-509 (1988).

${ }^{26}$ A. E. Hughes, "X-ray Electron Spectroscopy Study of Segregation Phenomena in Yttria-Zirconia Solid Electrolytes; Thesis. Royal Melbourne Institute of Technology, Melbourne, Australia, 1990.

${ }^{27}$ G. S. A. M. Theunissen, A. J. A. Winnubst, and A. J. Burggraat, "Surface and Grain Boundary Analysis of Doped Zirconia Ceramics Studied by AES and XPS," I. Mater. Sci., 27, 5057-66 (1990).

${ }^{28}$ T. G. Nieh, D. L. Yaney, and J. Wadsworth, "Analysis of Grain Boundaries in a Fine-Grained, Superplastic, Yttria-Containing, Tetragonal Zirconia," Scr. Metall., 23, 2007-12 (1989).

${ }^{20}$ A. J. Burggraaf, M. van Hemert, D. Scholten, and A. J. A. Winnubst, "Chemical Composition of Oxidic Interfaces in Relation with Electrical and Electrochemical Properties"; pp. 797-802 in Reactivity of Solids. Edited by P. Barret and L. C. Dufour. Elsevier Science Publishers, Amsterdam, Netherlands, 1985.

${ }^{30}$ M. L. Mecartney, "Influence of an Amorphous Second Phase on the Properties of Yttria-Stabilized Tetragonal Zirconia Polycrystals (Y-TZP)," J. Am. Ceram. Soc., 70 [1] 54-58 (1987).

${ }^{31}$ M. K. Cinibulk, H.-J. Kleebe and M. Ruihle, "Quantitative Comparison of TEM Technicues for Determining Amorphous Intergranular Film Thickness," J. Am. Ceram. Soc., 76 [2] 426-32 (1993).

${ }^{3}$ Y.-J. Lin, P. Angelini, and M. Mecartney, "Microstructural and Chemical Influences of Silicate Grain-Boundary Phases in Yttria-Stabilized Zirconia," J. Am. Ceram. Soc., 73 [9] 2728-35 (1990).

${ }^{73} \mathrm{M}$. Gust, G. Goo, J. Wolfenstine, and M. L. Mecartney, "Influence of Amorphous Grain Boundary Phases on the Superplastic Behavior of 3-mol\%-YtiriaStabilized Tetragonal Zirconia Polycrystals (3Y-TZP)," J. Am. Ceram. Soc., 76 [7] $1681-90$ (1993)

${ }^{34} \mathrm{C}$. O'Meara, G. L. Duniop, and R. Pompe, "Phase Relationships in the System $\mathrm{SiO}_{2}-\mathrm{Y}_{2} \mathrm{O}_{3}-\mathrm{Al}_{2} \mathrm{O}_{3}$ "; pp. 265-70 in High Tech Ceramics. Edited by P. Vincenzini. Elsevier Science Publishers B. V., Amsterdam, Netherlands, 1987.

${ }^{i 5}$ P. J. Wyllie and O. F. Tuttle, "Experimental Investigations of Silicate Systems Containing Two Volatile Components. Part II. The Effect of $\mathrm{NH}_{3}$ and HF, in Addition to $\mathrm{H}_{2} \mathrm{O}$ on the Melting Temperatures of Albitc and Granite," Am. J. Sci., 259, 128-43 (1961).

${ }^{36}$ D. A. C. Manning, "The Effect of Fluorine on Liquidus Phase Relationships in the System (Qz-Ab-Or) with Excess Water at $1 \mathrm{~kb}$," Contrib. Mineral. Petrol., 76, 206-15 (1981).

${ }^{37}$ M. F. Ashby and R. A. Verrall, "Diffusion-Accommodated Flow and Superplasticity," Acta Metall, 21, 149-63 (1973).

${ }^{38}$ D. R. Clarke, "Grain Boundaries in Polyphase Ceramics," J. Phys. C, 46 [C4] 51-59 (1985).

${ }^{39}$ S. P. S. Badwal and A. E. Hughes, "The Effects of Sintering Atmosphere on Impurity Phase Formation and Grain Boundary Resistivity in $\mathrm{Y}_{2} \mathrm{O}_{3}-\mathrm{Fully}$ Stabilized $\mathrm{ZrO}_{2}$, , J. Eur. Ceram. Soc, 9, 115-22 (1992).

${ }^{40}$ W. D. Kingery, H. K. Bowen, and D. R. Uhlmann, Introduction to Ceramics, 2nd ed; p. 766. Wiley, New York, 1976.

${ }^{4 !}$ D. R. Clarke, "On the Equilibrium Thickness of Intergranular Glass Phases in Ceramic Materials," J. Am. Ceram. Soc., 70 [1] 15-22 (1987). 